\title{
Enhancement of Phytoalexin Synthesis during Rice Blast Infection of Leaves by Pre-treatment with Carpropamid
}

\author{
Yasuo ARAKI and Yoshio KuRAHASHI \\ Laboratory for Disease Control, Yuki Research Centre, Nihon Bayer Agrochem K.K., \\ Nishi Hanjotsuka 9511-4, Yuki, Ibaraki 307-0001, Japan.
}

(Received March 23, 1999; Accepted July 2, 1999)

\begin{abstract}
Carpropamid $\{(1 R S, \quad 3 S R)$-2,2-dichloro- $N$-[1-(4-chlorophenyl) ethyl]-1-ethyl-3-methyl cyclopropanecarboxamide\}, which is considered as a melanin biosynthesis inhibitor, enhanced the accumulation of the phytoalexins momilactone A and sakuranetin in the rice leaves subsequently inoculated with the blast pathogen (Pyricularia oryzae). Carpropamid and its two diastereo-isomers, $\mathrm{A}(1 R, 3 S)$ and $\mathrm{B}(1 S, 3 R)$, did not stimulate phytoalexin production directly, but they potentiated rice plants to produce the two phytoalexins more rapidly and much amounts in response to blast infection. This phenomenon was also observed in rice leaves treated with WL28325 (2,2-dichloro-3,3-dimethylcyclopropane carboxylic acid), a resistance inducer. The calculation data of the correlation among accumulation of phytoalexins, concentrations of chemicals and biological effects suggested that the correlation pattern of isomer A resembled that of WL28325. The main mode of action of isomer A appears to be an enhancement of phytoalexin synthesis during blast infection (EPAS mode) similar to that of WL28325, rather than the inhibition of melanin biosynthesis (MBI mode). In contrast, the main mode of action of isomer B was found to be MBI, although EPAS probably also contributes to its biological activity. Carpropamid is assumed to control rice blast through a combination of MBI and EPAS activities.
\end{abstract}

Key words: carpropamid, phytoalexin, momilactone A, sakuranetin, plant resistant inducer, Pyricuralia oryzae.

\section{INTRODUCTION}

The importance of phytoalexins (PAs) has been investigated in various host/parasite systems, and some investigators have been able to demonstrate a positive correlation between phytoalexin synthesis and disease resistance. $^{1-4)}$ There are many reports concerning phytoalexin production in rice leaves as biological responses, such as momilactone $\mathrm{A}$ and fatty acids produced through the infection by blast fungus, ${ }^{5}$ oryzalexins and sakuranetin produced by stress, exposure to UV irradiation or treatment with jasmonate,$^{6-10)}$ oryzalexins and momilactones produced by treatment with heavy metals, ${ }^{11)}$ or momilactone A and sakuranetin produced by treatment with herbicides. ${ }^{12)}$ The first suggestion that chemical activation of rice defence mechanism could serve as a basis for crop protection was made by Cartwright $e t$ al. in $1977 .{ }^{13)}$ They reported that WL28325 ${ }^{14)}(2,2-$ dichloro-3,3-dimethylcyclopropane carboxylic acid, DDCP) did not stimulate phytoalexin production, but that it increased the responsiveness of rice to the infection caused by the blast fungus in terms of the synthesis of two phytoalexins, momilactone A and B. That is, DDCP activated rice defence mechanism. ${ }^{15)}$ At Nihon Bayer Agrochem and Bayer AG, the biological effects of cyclopropane derivatives were investigated, leading to the discovery of carpropamid(CRP), (1RS,3SR)-2,2dichloro- $N$-[1-(4-chlorophenyl)ethyl]-1-ethyl-3methylcyclopropane-carboxamide. ${ }^{16)}$ The mode of action of CRP was found to be melanin biosynthesis inhibition (MBI). ${ }^{17,18}$ CRP inhibits scytalone dehydratase (SDH) in the melanin-biosynthesis pathway of $P$. oryza $^{19)}$ : the activity of diastereo-isomer B is superior to that of isomer $\mathrm{A}^{20)}$ However, basic biological researches during the development period found the effects of CRP that could not be explained by an MBI mode-of-action, viz. CRP showed efficacy against some bacterial diseases though it had no direct activity for bacteria. We hypothesised that CRP might possess an additional mode of action, similar to that of DDCP, 
because the two compounds share a 2,2-dichloro cyclopropane carboxyl domain. We therefore investigated whether CRP and its two diastereo-isomers A or B enhance phytoalexin accumulation in rice leaves following inoculation with blast.

\section{MATERIALS AND METHODS}

\section{Chemicals}

Carpropamid (CRP), its main metabolite YRC1790 (cyclopropane 1-EtOH derivative of CRP) and WL28325 (2,2-dichloro 3,3-dimethylcyclopropane carboxylic acid, DDCP) were prepared by Yuki Research Centre (Nihon Bayer Agrochem K.K.). The diastereo-isomers of CRP, isomer $\mathrm{A}(1 R, 3 S)$ and isomer $\mathrm{B}(1 S, 3 R)$, were prepared by HPLC separation from CRP. Probenazole (PBZ) and tricyclazole (TCZ) were purchased from the supplier. The phytoalexin standards momilactone $\mathrm{A}$ and sakuranetin were supplied by Ibaraki University.

\section{Plant and Fungal Material}

Rice cultivar Kusabue (Pi-k) and a strain of P. oryzae, TH67-22 (race 031, pathogenic on Kusabue) were used in this study. The $P$. oryzae strain was grown on a medium containing a decoction of $50 \mathrm{~g}$ oatmeal, $30 \mathrm{~g}$ sucrose and $20 \mathrm{~g}$ agar per liter. Then the aerial hyphae were removed from 5-day-old cultures grown at $25^{\circ} \mathrm{C}$ using a thin plastic plate and conidiation was induced by incubating under BLB light (FL20S, 20W, Toshiba Co., Tokyo) for 10 days. Conidia were removed from the cultures using a paintbrush and suspended in sterilised water with Tween $20(1 / 4000, v / v)$, then filtered through two layers of muslin. Conidial numbers were counted using a haemocytometer.

\section{Chemical Treatment and Inoculation}

Six rice seedlings, grown to the 1.5-2 leaf stage in a nursery box, were transplanted into the hydroponic culture containing $60 \mathrm{ml}$ ammonium sulphate $(500 \mathrm{ppm})$ and either spiked with or without the test chemicals, and cultivated for 5 days in a greenhouse. For an investiga-

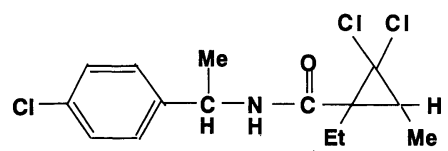

carpropamid (KTU3616, CRP)

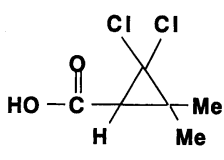

WL28325 (DDCP)

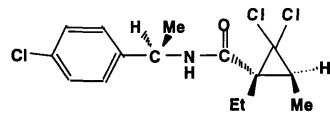

isomer $\mathrm{A}:\left(1 R, 3 S, 1^{\prime} R\right)$

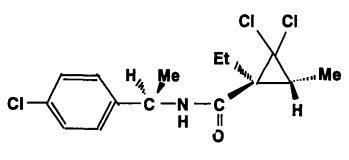

isomer $\mathrm{B}:\left(1 S, 3 R, 1^{\prime} R\right)$
Fig. 1 Chemical structure of carpropamid, its diastereo isomers and WL28325. tion of the accumulation of phytoalexins, $10 \mu \mathrm{l}$ agar gel containing 4000 blast conidia and Tween 20 were droplet-inoculated, five droplets to each of the 3rd leaf on six replicate plants. The inoculated plants were then transferred to a glass chamber with high humidity and kept in the greenhouse. Control plants were inoculated with agar gel without blast conidia. For testing a biological activity, a $2 \times 10^{5} / \mathrm{ml}$ suspension of blast conidia was sprayed onto plants 5 days after treatment, after which plants were kept for 1 day at $25^{\circ} \mathrm{C}$ with approximately $100 \%$ relative humidity. The plants were then kept for a further 6 days in a greenhouse, after which the area of leaf surface with symptoms of rice blast was estimated.

\section{Analytical Estimation of Momilactone A or Saku- ranetin Accumulation in Rice Leaves}

Thirty leaf segments, each ca. $3 \mathrm{~mm} \times 3 \mathrm{~mm}$ square, were sampled daily from one day to 6 days after gel inoculation. The sampled leaf segments were kept submerged in $5 \mathrm{ml}$ of an organic solvent mixture (ethyl acetate $/$ methanol $=4: 1, \mathrm{v} / \mathrm{v}$ ) for 2 days at $4^{\circ} \mathrm{C}$. The respective extracts and the rinsing from the vessels were then combined, and the organic solvent was evaporated to dryness by rotary evaporation in vacuo. The extracts were next dissolved in a small amount of methanol. The whole solution was applied to a TLC plate (Kieselgule F-254, Merck 5715) and developed with a solvent system (cyclohexane/1,4-dioxane $=7 / 3, \mathrm{v} / \mathrm{v}$ ). The phytoalexins were co-spotted for reference. Movement of momilactone $\mathrm{A}$ and sakuranetin after development was determined by heating the momilactone A-spotted lane on the TLC plate after spraying with $50 \% \mathrm{H}_{2} \mathrm{SO}_{4}$ in $\mathrm{MeOH}$, or by observation of the spot for sakuranetin under UV light $(254 \mathrm{~nm})$. The silica gel zones $(R f$ 0.20-0.22 for momilactone $\mathrm{A}$ and $R f 0.31-0.33$ for sakuranetin) were then scraped from the TLC plate. Each scraped zone was extracted in a solvent mixture (chloroform/ethanol $=8 / 2, \mathrm{v} / \mathrm{v}$ ) by ultra-sonication. The organic solvent of the extracts was evaporated to dryness by rotary evaporation in vacuo and the residues were dissolved in $100 \mu 1$ of ethyl acetate or acetonitrile. One $\mu \mathrm{l}$ of the ethyl acetate solution was injected into a GC/ MS/SIM system (HP5995) equipped with a fused silica capillary column Rtx-50(0.25 $\mathrm{mm} \times 30 \mathrm{~m}, 0.25 \mu \mathrm{m}$ thickness of phenylmethyl polysiloxane: Restek). The level of momilactone A was determined by comparing the peak area for $\mathrm{m} / \mathrm{z} 199$ or 314 with that of the standard. Twenty $\mu 1$ of the acetonitrile solution was injected into an HPLC system (HP1090) equipped with a LiChrospher 100 RP-18 column $(5 \mu \mathrm{m}, 4 \mathrm{~mm}$ id. $\times 250 \mathrm{~mm}$ : Merck) and eluted with acetonitrile- $0.02 \mathrm{~N}$ formic acid ( 1 $\mathrm{ml} / \mathrm{min}$, liner gradient from 10-100\% acetonitrile/0.5-22 min). Sakuranetin was detected by UV-detection at 285 $\mathrm{nm}$ and the level determined by comparing the peak area 
with that of the standard. All of the analytical data were calculated as ng/30 leaf segments. The detectable limits of momilactone $\mathrm{A}$ and sakuranetin were 30 and 25 ng/30 leaf segments, respectively. In the preliminary trials, the detectable limits of momilactone A and sakuranetin were $150 \mathrm{ng}$ and $60 \mathrm{ng}$, respectively.

\section{RESULTS}

\section{Protective Activities of the Chemicals against Rice Blast}

The efficacy of MBIs, namely CRP, isomer B and TCZ against rice blast was very high and stable in spite of relatively low application rates. One ppm treatment of CRP, isomer B and TCZ to a hydroponic culture showed the efficacy (PV, abott) 95, 93 and 90, respectively. In contrast, the efficacy of isomer $\mathrm{A}$ and the plant resistance inducers DDCP and PBZ against blast infections was moderate. Five ppm application of isomer A, DDCP and probenazole resulted in the efficacy PV(abbot) 71, 70 and 50, respectively. YRC1790, the main metabolite of CRP in the rice plant, did not show any efficacy.

\section{Accumulation of Momilactone $A$ and Sakuranetin in Rice Leaves after Inoculation with a Compatible Strain of Blast Fungus}

$P$. oryzae infection of leaves treated with $5 \mathrm{ppm}$ CRP, DDCP or PBZ induced a more rapid and extensive accumulation of momilactone $A$ than did infection of untreated leaves (Fig. 2). Momilactone A was first detected in the treated and infected leaves from 1 day (DDCP) to 2 days (CRP,PBZ) after inoculation. In contrast, TCZ- or YRC1790-treated leaves accumulated little momilactone $\mathrm{A}$ and its pattern of accumulation was almost the same as in untreated, inoculated leaves. In CRP, CPCA or PBZ-treated rice leaves, a peak of accumulation of momilactone A was observed 5 days after inoculation. A weak accumulation of momilactone A was observed in leaves which were treated with CRP, CPCA or PBZ and agar gel alone (data not shown). It could be interpreted that the stress of gel treatment induced phytoalexin accumulation weakly, but the level of accumulation was not as great as in the untreated, inoculated rice leaves, and the time of first detection was 3 days after gel treatment. No accumulation of momilactone A was observed in leaves which were treated with chemicals but not inoculated $(<150 \mathrm{ng} / 30$ leaf segments). As for the accumulation of sakuranetin, similar results were obtained from CRP, DDCP or PBZ-treated leaves after inoculation with P. oryzae (Fig. 3). In TCZ- or YRC1790-treated leaves, there was little accumulation of sakuranetin, however a high level of sakuranetin was accumulated in leaves that were treated with TCZ 6 days after inoculation. No accumulation of sakuranetin was observed in leaves which were treated with the chemicals but not inoculated $(<60 \mathrm{ng} / 30$ leaf

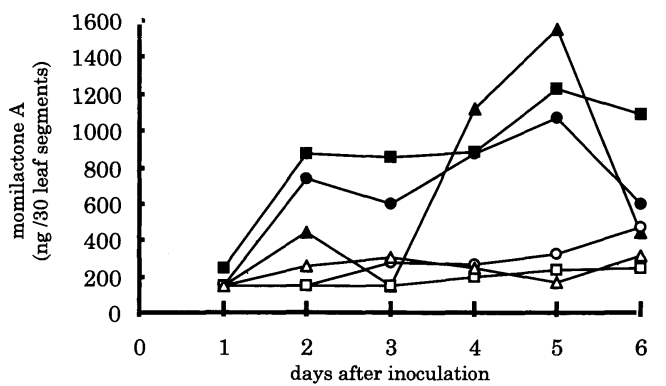

Fig. 2 Accumulation of momilactone A in rice leaves (c.v.

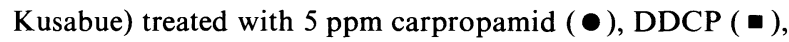
probenazole $(\Delta)$, tricyclazole $(O)$, YRC1790 ( $\square$ ) or untreated $(\triangle)$ in hydroponic medium 5 days after inoculation with compatible blast strain TH67-22 (race 031). Each point is the mean of two to four replicates.

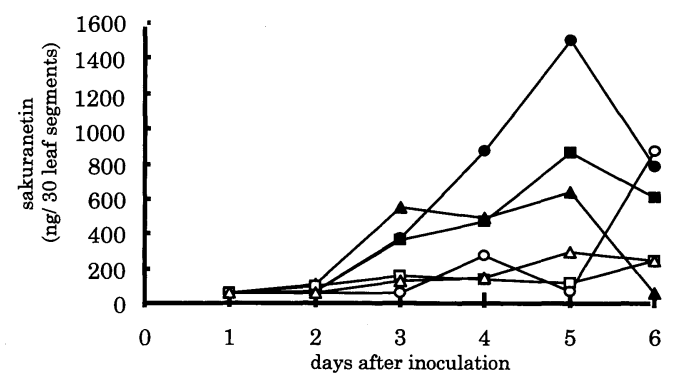

Fig. 3 Accumulation of sakuranetin in rice leaves (c.v.

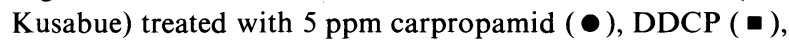
probenazole ( $\triangle$ ), tricyclazole ( $O$ ), YRC1790 ( $\square$ ) or untreated $(\triangle)$ in hydroponic medium 5 days after inoculation with compatible blast strain TH67-22 (race 031). Each point is the mean of two to four replicates.

segments, data not shown). High levels of sakuranetin were detected 3 days after inoculation in CRP, DDCP or PBZ-treated leaves. A peak of accumulation was observed in CRP and DDCP-treated rice leaves 5 days after inoculation. As for PBZ, no obvious accumulation peak was observed. However, the accumulation peaked at 3 days after inoculation and the pattern of accumulation was clearly different from that of TCZ, YRC1790 or the untreated and the inoculated rice leaves.

Validation studies of the abilities of CRP, its isomers and DDCP to enhance the accumulation of PAs in rice leaves after inoculation with blast were performed in various application concentrations. Large amounts of momilactone A accumulated in leaves from 2 days after inoculation at all concentrations of CRP (94-204 ng/30 leaf segments at $0.5,1,3$ or $5 \mathrm{ppm}$ applied). The accumulated amounts seemed to reach a plateau 4 days after inoculation (277-625 ng/30 leaf segments). The accumulation pattern of momilactone A following treatment with $5 \mathrm{ppm}$ of the two isomers was very similar to that of CRP. In contrast, in the case of the low concentration treatment $(0.25$ or $0.5 \mathrm{ppm})$, the accumulation of 
momilactone A was lower in isomer B-treated leaves and its pattern was almost the same as in untreated leaves. However, the accumulation of the phytoalexin did not decrease in CRP- or isomer A-treated leaves (62-805 ng/ 30 leaf segments) following treatment with low concentrations $(0.25$ or $0.5 \mathrm{ppm})$. The accumulation pattern of momilactone A in DDCP-treated leaves was very similar to that of isomer A. As for sakuranetin, accumulation was not observed in all leaf samples one day after inoculation ( $<25 \mathrm{ng} / 30$ leaf segments). In $1.5,0.5$ or 0.25 ppm of isomer A-treated leaves, the accumulation pattern was similar to that in the untreated and the inoculated leaves. These results suggest that the relative effects of CRP, its isomers or DDCP on PA-induction vary according to length of time after inoculation and concentration applied.

\section{DISCUSSION}

In the reports of Cartwright et al., ${ }^{13,15)}$ blast inoculation was performed after wounding the rice leaves with suspension of blast conidia. In our preliminary test, we compared the accumulated amounts of phytoalexins following wound or non-wound inoculation with agar gel containing blast conidia. It was clear that larger amounts of sakuranetin accumulated in the non-woundinoculated rice leaves than in the wound-inoculated leaves treated with CRP or DDCP. In contrast, accumulation of momilactone A was observed for both inoculation methods in the leaves treated with CRP or DDCP. So we adopted non-wound inoculation with agar gel containing blast conidia. In the case of the noninoculated leaves, i.e. those rèceiving agar gel without blast conidia, the accumulation of phytoalexins was not observed having no connection with treatment of compounds. Accordingly, the large amount of phytoalexins which accumulated in the inoculated leaves was obviously induced by the chemical treatment and blast inoculation. Our results show that DDCP also has the ability to enhance sakuranetin production after inoculation with blast alongside the accumulation of momilactone $A$ as reported by Cartwright et al. ${ }^{13,15)} \mathrm{PBZ}$, a plant resistance inducer, enhanced the accumulation of the phytoalexins after blast inoculation in our preliminary experiments. Sekizawa et $a{ }^{21}{ }^{21}$ has already reported that PBZ-treated and blast inoculated rice leaves did not show any accumulation of momilactone A or B. Our sampling was done later after inoculation than their trial. TCZ is a blasticide and its mode of action is categorised as that of MBI. ${ }^{22)}$ This compound did not show any induction of phytoalexins following inoculation with blast conidia. However, CRP, a MBI compound, clearly enhanced the accumulation of phytoalexins after blast inoculation. In our preliminary test using some CRP related compounds without a cyclopropane domain in their chemical structure but with a clear MBI activity, there was no accumulation of phytoalexins after blast inoculation. Accordingly, the ability of CRP is assumed to be related to its dichlorocyclopropane domain. Treatment with YRC 1790, the main plant metabolite of CRP, did not enhance PA accumulation after blast inoculation. This metabolite shows no MBI activity and cannot control rice blast. These data suggest that the accumulation of PAs observed in CRPtreated rice leaves after inoculation is mediated by CRP itself. Using the data of validation studies, we confirm the relationship between the concentration applied, the extent of the enhancement of PA-induction and the biological activity of CRP, its two isomers and DDCP. In the analysis, we changed the accumulation data for PAs to an accumulation ratio (AR), where AR of PA= PA in the treated leaves/PA in the untreated leaves at a given time after inoculation. The relationship between biological activity against rice blast and treatment concentrations of chemicals was estimated. The relationship between biological activity ( $Y$ : PV) and treated concentration of chemicals ( $X$ :ppm) was calculated: $Y=$ $2.636 \operatorname{Ln}(X)+94.9 \quad\left(\mathrm{CRP}, \quad R^{2}=0.997\right), \quad Y=4.963$ $\mathrm{Ln}(X)+92.0$ (isomer $\mathrm{B}, R^{2}=0.997$ ), $Y=-3.622 X^{2}+$ 32.0 (isomer $\mathrm{A}, R^{2}=0.906$ ) and $Y=-1.832 X^{2}+23.5$ (DDCP, $R^{2}=0.975$ ), respectively. Since CRP is consisted of a $1: 1$ mixture of isomers $\mathrm{A}$ and $\mathrm{B}$, its biological activity seems to be through a combined contribution of the two isomers. However, it is easily seen that the activity of CRP owes most to that of isomer B, a strong $\mathrm{SDH}$ inhibitor. The activity of isomer $\mathrm{A}$ was relatively moderate, and the relationship between the activity and treatment concentration was similar to that of DDCP, an enhancer of the accumulation of PAs. The correlation coefficient between concentration applied and AR for the chemicals was estimated. For the accumulation of momilactone A, DDCP showed a high correlation coefficient 2 or 3 days after inoculation. This indicates that the accumulation of momilactone $A$ is dependent on the treatment concentration of DDCP at 2 or 3 days after inoculation $(R=0.888,0.964)$. However, the high correlation coefficient disappeared at 4 days after inoculation ( $R=0.236$ ). In the case of CRP and its two isomers, the correlation coefficient also varied according to length of time. In case of isomer $\mathrm{B}$, the correlation coefficient was relatively high from 4 days after inoculation $(R=0.982$, 0.868 or 0.849 at 4,5 and 6 days after inoculation, respectively). For CRP, the correlation coefficient increased to $0.763(=R)$ at 3 days after inoculation. As for sakuranetin, all of the chemicals showed their best correlation coefficients at 3 days after inoculation (from $0.755=R$ of isomer $\mathrm{B}$ to $0.975=R$ of isomer $\mathrm{A}$ ). $\mathrm{DDCP}$ and isomer A showed a high correlation coefficient from 3 to 6 days after inoculation. Thus the results of isomer A were very similar to those of DDCP. This similarity was also observed in the relationship between AR and biological 


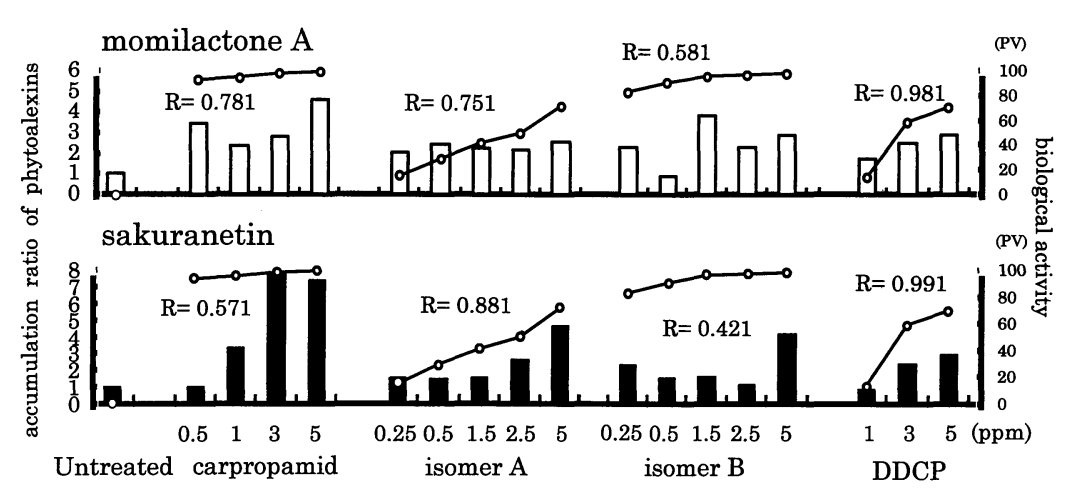

Fig. 4 Correlation between the accumulation ratio (AR) of phytoalexins, biological activity against rice blast and treatment concentration of carpropamid, isomer A, isomer B or DDCP 3 days after inoculation. The bars, $\square$ and $\square$, indicate the AR of momilactone A or sakuranetin, respectively. The mark " $O$ " means biological activity of each treated conc. of chemicals at 7 days after inoculation, and $(R)$ is correlation coefficient between AR of phytoalexins and biological activity.

activity assessed at 7 days after inoculation.

As for sakuranetin, isomer A and DDCP showed high correlation coefficients between AR at 3 days after inoculation and effectiveness at 7 days after inoculation $(R=$ 0.991 in DDCP and 0.881 in isomer A). On the other hand, isomer B did not show a high correlation between accumulation of sakuranetin and effectiveness. As for momilactone A, DDCP also showed a high correlation coefficient at 3 days after inoculation $(R=0.981)$. CRP maintained a relatively high correlation between accumulation of momilactone $\mathrm{A}$ and effectiveness from 2 to 6 days after inoculation ( $R=0.761-0.851)$. As for isomer $\mathrm{A}$, the correlation coefficient increased at 3 days after inoculation $(R=0.751)$. On the other hand, isomer $\mathrm{B}$ showed a relatively moderate correlation coefficient $(R=$ 0.581 at 3 days after inoculation). A summary of the correlation between PA accumulation and biological effectiveness at 3 days after inoculation is shown in Fig. 4. For isomer B, a strong SDH inhibitor, the correlation coefficient was relatively low. However, an obvious accumulation of PAs was observed. CRP showed a relatively high correlation coefficient for momilactone $\mathrm{A}$. MBI activity of isomer A was weaker than that of isomer B: however, isomer A can control rice blast as well as DDCP. Its main mode of action seems to be an enhancement of phytoalexin synthesis after blast inoculation (EPAS) mode, like DDCP. In contrast, the main mode of action of isomer $B$ seems to be MBI. The EPAS mode also contributes to the effectiveness of CRP for blast control. These results indicate that CRP controls rice blast through a combination of the MBI mode of isomer B and the EPAS activity of isomer A.

\section{ACKNOWLEDGMENTS}

The authors would like to express gratitude to Professor Kodama of Ibaraki University for providing us with analytical standards for the phytoalexins and his kind supervision of this paper.

\section{REFERENCES}

1) M. G. Hahn \& H. Griseback: Plant Physiol. 77, 591-601 (1985)

2) T. Waldmüller \& H. Griseback: Planta 172, 424-430 (1987)

3) J. S. Huang \& R. Baker: Plant Physiol. 96, 1302-1307 (1991)

4) P. E. Schmidt, M. Parniske \& D. Warner: Bot. Acta 105, 1825 (1992)

5) W. X. Li, O. Kodama \& T. Akatsuka: Agric. Biol. Chem. 55 (4), 1041-1047 (1991)

6) O. Kodama, J. Miyakawa, T. Akatsuka \& S. Kiyosawa: Phytochemistry 31 (11), 3807-3809 (1992)

7) H. Kato, O. Kodama \& T. Akatsuka: Arch. Biochem. Biophys. 316 (2),707-702 (1995)

8) R. Rakwal, M. Hasegawa \& O. Kodama: Biochem. Biophys. Res. Commun. 222, 732-735 (1996)

9) R. Rakwal, S. Tamogami \& O. Kodama: Biosci. Biotech. Biochem. 60(6), 1046-1048 (1996)

10) O. Kodama: Mycotoxins 42, 7-11 (1996)

11) O. Kodama, A. Yamada, A. Yamamoto, T. Takemoto \& T. Akatsuka : J. Pesticide Sci. 13, 615-617 (1988)

12) S. Tamogami, O. Kodama, K. Hirose \& T. Akatsuka: J. Agric. Food Chem. 43, 1695-1697 (1995)

13) D. Cartwright, P. Langcake, R, J. Pryce \& D. P. Leworthy: Nature 267, 511-513 (1977)

14) P. Langcake \& S.G.A. Wickins: Physiol. Plant Pathol. 7, 113-126 (1975)

15) D. W. Cartwright \& P. Langcake: Physiol. Plant Pathol. 17, 259-267 (1980)

16) T. Hattori, Y. Kurahashi, T.Konze \& S.Kagabu: Brighton Crop Protect. Conf. Proc. 2, 517 (1994)

17) Y. Kurahashi, S. Sakawa, T. Kinbara, K. Tanaka \& S. Kagabu: J. Pesticide Sci. 22, 108-112 (1997)

18) Y. Kurahashi, Y. Araki, T. Kinbara, R. Pontzen \& I. Yamaguchi: J. Pesticide Sci. 23, 22-28 (1998)

19) T. Motoyama, K. Imanishi, T. Kinbara, Y. Kurahashi \& I. Yamaguchi: J. Pesticide Sci. 23, 58-61 (1998)

20) S. Kagabu \& Y. Kurahashi: J. Pesticide Sci. 23, 145-147 (1998)

21) Y. Sekizawa \& T. Watanabe: J. Pesticide Sci. 6, 247-255 
(1981) (in Japanese)

22) I. Yamaguchi, S. Sekido \& T. Misato: J. Pesticide Sci. 7, 523-529 (1982)

\section{要 約}

カルプロパミド前処理イネにおけるイネいもち病菌 感染によるファイトアレキシン合成の増強

新木康夫, 倉橋良雄

メラニン生合成阻害剂（MBI）であるカルプロパミド (CRP) を処理したイネ葉にいもち病菌を接種すると, イネ のファイトアレキシン (PA) であるモミラクトン A とサク ラネチンが多量に蓄積した. CRP またはその主成分である isomer $\mathrm{A}(1 R, 3 S), \mathrm{B}(1 S, 3 R)$ をそれぞれ単独で処理した だけではPAの蓄積は認められなかったが，いもち病菌を 接種することにより速やかにかつ多量にイネ葉において生 成，蓄積することが明らかとなった。この現象は抵抗性誘 導剂 WL28325 処理イネ葉においても同様に認められ，そ の処理濃度, 防除効果及び PA 蓄積量の相互相関性を解析 した結果，isomer A が最も類似したパターンを示した。 MBI 活性が isomer B に劣る isomer A の主たる作用機構は いもち病菌感染による PAの蓄積増強作用であると推定さ

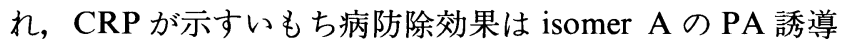
蓄積増強と, isomer B の MBI による相互作用により得られ ていることが示唆された。 